\title{
Structure and reactivity in neutral organic electron donors derived from 4-dimethylaminopyridine
}

\author{
Jean Garnier ${ }^{1}$, Alan R. Kennedy ${ }^{1}$, Leonard E. A. Berlouis ${ }^{1}$, \\ Andrew T. Turner ${ }^{2}$ and John A. Murphy ${ }^{* 1}$
}

\section{Full Research Paper}

Address:

${ }^{1}$ WestCHEM, Department of Pure and Applied Chemistry, University of Strathclyde, 295 Cathedral Street, Glasgow G1 1XL, U.K. and 2PR\&D Laboratory Building, AstraZeneca, Silk Road Business Park, Charterway, Macclesfield SK10 2NA, United Kingdom

\section{Email:}

Jean Garnier - jeangarn@hotmail.com; Alan R. Kennedy a.r.kennedy@strath.ac.uk; Leonard E. A. Berlouis I.berlouis@strath.ac.uk; Andrew T. Turner andrew.t.turner@astrazeneca.com; John A. Murphy* john.murphy@strath.ac.uk

* Corresponding author

\section{Keywords:}

dication; 4-DMAP; electron donor; electron transfer; radical cation; redox; reduction

\begin{abstract}
Beilstein J. Org. Chem. 2010, 6, No. 73. doi:10.3762/bjoc.6.73
\end{abstract}
Received: 27 April 2010

Accepted: 09 June 2010

Published: 05 July 2010

Guest Editor: J. Murphy

(c) 2010 Garnier et al; licensee Beilstein-Institut.

License and terms: see end of document.

\begin{abstract}
The effects on the redox properties of modifying the molecular skeleton of neutral bis-2-(4-dimethylamino)pyridinylidene electron donors, derived from 4-dimethylaminopyridine (4-DMAP), have been explored, by varying two parameters: (i) the length of a polymethylene chain linking the two pyridine-derived rings and (ii) the nature of the nitrogen substituents on the 4 and $4^{\prime}$ positions of the precursor pyridines. Restricting the bridge length to two methylene units significantly altered the redox profile, while changes in the nitrogen-substituents at the 4 and 4 ' positions led to only slight changes in the redox potentials.
\end{abstract}

\section{Introduction}

Neutral organic compounds $\mathbf{1}$ and 4-10 (Figure 1) have attracted considerable attention as ground-state electron donors [1-38], and many are now being employed as reagents in organic transformations. Such a range of reagents with different redox potentials leads to the expectation of considerable selectivity in their reductions of organic substrates, and evidence is steadily accumulating to support this. Tetrathiaful- valene (TTF, $1, E^{1}{ }_{1 / 2}=0.37 \mathrm{~V} ; E^{2}{ }_{1 / 2}=0.67 \mathrm{~V}$ in DCM vs SCE) [1], one of the weakest of these donors, reduces arenediazonium salts to aryl radicals [2-12], but is not strong enough to react with alkyl and aryl halides. The driving force for its oxidation is the attainment of some degree of aromaticity in the formation of its radical cation salt $\mathbf{2}$ on the loss of one electron, and full aromaticity in its dication salt $\mathbf{3}$ on loss of two elec- 


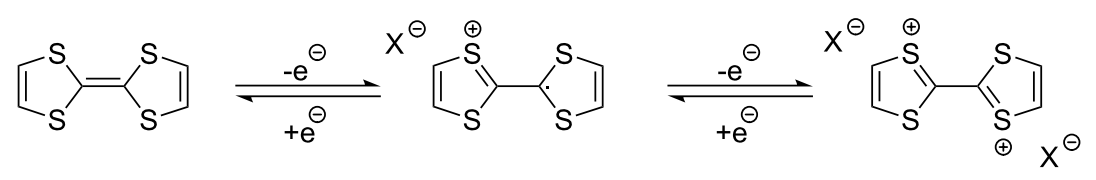

1<smiles>C1=CSC(=c2ccc(=C3SC=CS3)cc2)S1</smiles>

4
2<smiles>CN(C)C(N)=C(N(C)C)N(C)C</smiles>

5<smiles>CN1C2=C3N(C)c4ccccc4N3CCCN2c2ccccc21</smiles>

6
3<smiles>C1=CN2CCCN3C=CN(CCC1)C2=C3</smiles>

7<smiles>CNC1=CC2=C3C=C(N(C)C)C=CN3CCCN2C=C1</smiles>

Figure 1: Neutral organic electron donors 1 and 4-10.

trons, as well as the stabilization of both the positive charge and radicals by the lone pairs on the sulfur atoms. The effect of aromatic stabilization is enhanced in the extended analogue 4; however, unlike TTF, this compound affords only an irreversible oxidation $E_{\mathrm{p}}=-0.14 \mathrm{~V}$ in $\mathrm{MeCN}$ (assuming that the reported value is measured relative to SHE, that would correspond to $-0.38 \mathrm{~V}$ vs SCE) [13]. Tetrakis-dimethylaminoethene (TDAE, 5: $E_{1 / 2}^{1}=-0.78 \mathrm{~V} ; E^{2}{ }_{1 / 2}=-0.61 \mathrm{~V}$ vs SCE in MeCN) is a stronger reducing agent and converts electron-deficient alkyl bromides to the corresponding anions [14-17] and notably the iodide $\mathrm{CF}_{3}-\mathrm{I}$ to trifluoromethyl anion, ${ }^{-} \mathrm{CF}_{3},[15]$ but is not powerful enough to react with aryl halides. Despite not experiencing any aromatic stabilization on oxidation, the molecule is such a good donor as a result of the ability of the nitrogen atoms in $\mathbf{5}$ to stabilize both the positive charge and an unpaired electron upon oxidation; this stabilization is greater than is afforded by sulfur in TTF.

Benzimidazole-derived donor $6\left(E^{1}{ }_{1 / 2}=-0.82 \mathrm{~V} ; E^{2}{ }_{1 / 2}=\right.$ $-0.76 \mathrm{~V}$ vs SCE in DMF) [18-20], combines the stabilization of positive charge and of an unpaired electron provided by four nitrogens, with aromatic stabilization in its oxidised forms. This exceptional donor has the power to reduce aryl iodides $\left(E^{0}=\right.$ $-2.2 \mathrm{~V}$ ) to aryl radicals, but not to aryl anions [21]. This is paradoxical in view of the standard potential of the second step; $E^{0}$ $=0.05 \mathrm{~V}$ vs SCE in MeCN for the conversion of an aryl radical to an aryl anion [39]. Whatever about the standard potentials, in practice, the formation of aryl anions is only observed when the electron donor has $E_{1 / 2}=-1 \mathrm{~V}$ or is more negative [40]. In line with this, both the imidazole-derived donor $7\left(E_{1 / 2}=-1.20 \mathrm{~V}\right.$ vs $\mathrm{SCE}$ in DMF) [22-25] and the 4-dimethylaminopyridine (4-DMAP)-derived donor $8\left[E_{1 / 2}(\mathrm{DMF})=-1.69 \mathrm{~V}\right.$ vs $\left.\mathrm{Fc} / \mathrm{Fc}^{+}\right]$ [26-29], which would equate to $-1.24 \mathrm{~V}$ vs SCE $[E$ $(\mathrm{DMF})_{\mathrm{Fc} / \mathrm{Fc}+}=0.45 \mathrm{~V}$ vs SCE] [41] react with aryl iodides to afford aryl anions. As an indication of their enhanced donor properties, these two donors can also cleave appropriate arenesulfonamides [25], aryl alkyl sulfones [25,26], Weinreb amides [28] and acyloin derivatives [29]. They are also prone to transfer two electrons rather than one, with the cyclic voltammogram (c.v.) of $\mathbf{8}$ showing a single 2-electron reversible redox wave [26] while in donor 7 the potentials of the successive electron transfers are close enough that the c.v. gives the appearance of a single reversible peak, but has a slight shoulder [24]. Molecules $9\left(E_{1 / 2}=-1.00 \mathrm{~V}\right.$ vs SCE in DMF) [30-32] and 10 $[33,35,37]$ extend the range of designs of neutral organic electron donors, although we are not aware of them being investigated as yet for the reduction of organic substrates.

In order to design both more potent electron donors, and donors with calibrated and targeted properties, the factors that drive the electron transfer(s) need to be clearly understood, and this paper now probes two factors that could impact on that. 


\section{Results and Discussion}

Donor 8 has a number of attractive features. It is simply prepared from the reaction of 4-DMAP with 1,3-diiodopropane, followed by treatment of the product with base [26-28]. A wide range of analogues of 4-DMAP, which have been well studied in acylation chemistry $[42,43]$, is already available. This suggests that preparation of analogues of $\mathbf{8}$ should also be straightforward. Hence, donor $\mathbf{8}$ was selected as the target for modification. The effect of modifying the length of a polymethylene chain linking the two pyridine-derived rings and the nature of the substituents on the 4- and 4'-positions of those pyridine rings were the points of particular interest. TDAE, $\mathbf{5}$, has been used extensively as a two-electron transfer reagent, and many salts that feature its dication have been analysed by $\mathrm{X}$-ray crystallography [44]. In these dications, the two ends of the molecule are twisted extensively to minimize interaction between the two positive charges. It is tempting to think that the degree of twist is linked to the power of the reducing agent. If twisting was not possible, then the driving force for removal of the second electron, for the conversion of the radical cation to the dication, should be diminished. To see if the same twist occurs with our donor $\mathbf{8}$, the crystal structure of the disalt $\mathbf{1 7}$ was determined [twist $(\mathrm{N}-\mathrm{C}-\mathrm{C}-\mathrm{N}=52.5(3)$ degrees] (Figure 2). The degree of twist is limited by the three-carbon chain - a longer chain should afford greater flexibility and might afford a stronger donor, mirroring the findings of Ames et al. with a different series of compounds [18-20,22]. In contrast, shortening the polymethylene chain as in $\mathbf{1 4}$ should constrain rotation of the pyridine rings in the dication 16, and hence make formation of $\mathbf{1 6}$ more difficult. To determine the effect of bridge-length on redox potential, the analogous donors 14 and 15 were prepared in situ and converted to their respective oxidized salts $\mathbf{1 6}$ and 18, as shown in Figure 2, by reaction with iodine. Anion exchange to afford the corresponding hexafluorophosphate salts $\mathbf{1 6}^{\prime}$ and $\mathbf{1 8}^{\prime}$ was then carried out prior to cyclic voltammetry. (The iodide anions were exchanged since iodide ions would be electrochemically active, albeit at more positive potentials than feature in our studies.)

Cyclic voltammetry studies were carried out by adding deoxygenated solutions of the oxidized disalts $\mathbf{1 6}^{\prime}-\mathbf{1 8}^{\prime}$ (rather than the electron donors) to the electrochemical cell and then carrying out the electrochemistry under an inert gas. The donors themselves are highly sensitive to traces of oxygen, and so are less convenient to weigh out than the disalts. All of the cyclic voltammograms showed reversible redox chemistry, featuring the transfer of two electrons, as indicated by calibration with ferrocene/ferrocenium $\left(\mathrm{Fc} / \mathrm{Fc}^{+}\right)$.

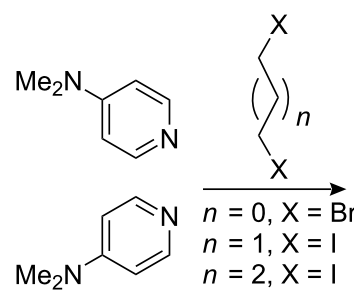<smiles>[Y]OC1CCCCC1[n+]1ccc(N(C)C)cc1</smiles>

$11, n=0,64 \%$

12, $n=1,98 \%[20]$

$13, n=2,97 \%$

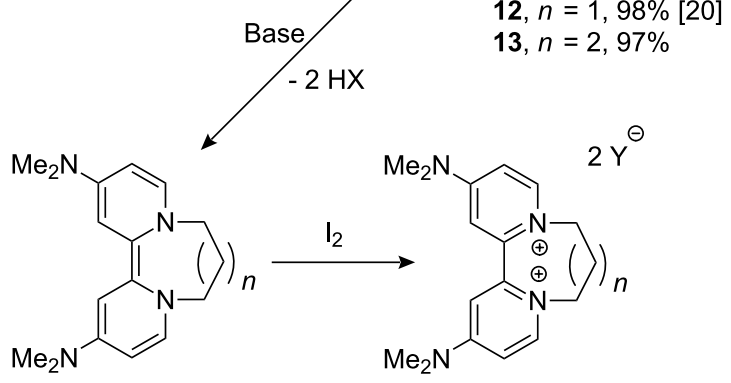

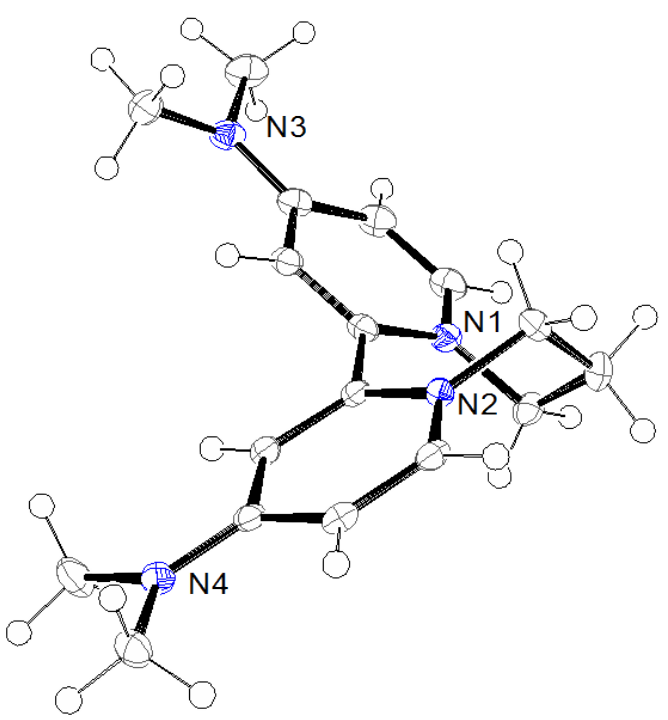

X-ray structure of $\mathbf{1 7}$

16', $n=0, Y=\mathrm{PF}_{6}, 41 \%$ over 3 steps

17, $n=1, Y=1,99 \%$

$17, n=1, Y=P_{6}, 84 \%$

$15, n=2$

18, $n=2, Y=1$

18', $n=2, \mathrm{Y}=\mathrm{PF}_{6}, 76 \%$ over 3 steps

Figure 2: Formation of donors and oxidation to form diiodide salts, together with the ORTEP diagram of diiodide salt 17 (only the cation is shown). 


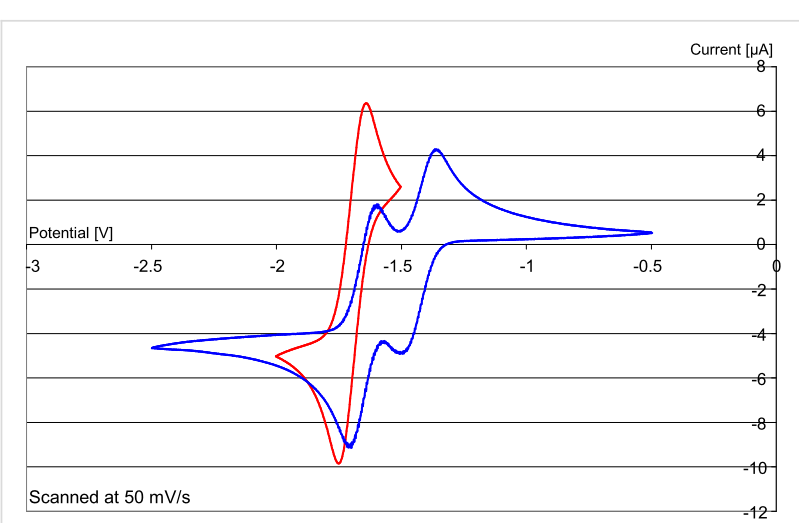

Figure 3: Cyclic voltammograms vs $\mathrm{Fc} / \mathrm{Fc}^{+}$of $17^{\prime} \leftrightarrow 8$ (red) and $16^{\prime} \leftrightarrow$ 14 (blue)

Restricting the bridge length to two carbons made donor 14 a less effective reducing agent (Figure 3) compared to $\mathbf{8}$, underlining the importance of flexibility of the inter-ring bond. Here, donor 8 shows a single two-electron wave $\left[E^{1}{ }_{1 / 2}(\mathrm{DMF})=\right.$ $-1.24 \mathrm{~V}$ vs SCE (calibrated using $\mathrm{Fc} / \mathrm{Fc}^{+}$)], while donor 14 shows two one-electron waves $\left[E^{1}{ }_{1 / 2}(\mathrm{DMF})=-1.21 \mathrm{~V}\right.$, and $E^{2}{ }_{1 / 2}(\mathrm{DMF})=-0.98 \mathrm{~V}$ vs SCE (calibrated using $\left.\left.\mathrm{Fc} / \mathrm{Fc}^{+}\right)\right]$. The potential for loss of the first electron is similar in both compounds; however, the loss of the second electron from $\mathbf{8}$ is about $300 \mathrm{mV}$ more negative than from 14. This indicates a greater driving force for loss of the second electron in $\mathbf{8}$ than in $\mathbf{1 4}$ consistent with the predicted difficulty in forming $\mathbf{1 4}$ as an essentially planar dication, where repulsion between the two charges would be more severe.

In contrast, comparison of the cyclic voltammograms of $\mathbf{1 8}^{\prime}$ and 17' (Figure 4a) showed only minor differences, with both showing a single wave corresponding to a two-electron reversible process at essentially the same potential (within $10 \mathrm{mV}$ ), so the increased flexibility does not benefit the two-electron donor
15 relative to 8 . Taking the idea of flexible rotation between the two halves of the molecule to its limit, we prepared compound 20' [27] (Figure 5) and determined its cyclic voltammetric behaviour. As shown in Figure $4 \mathrm{~b}$, this $\left[E_{1 / 2}(\mathrm{DMF})=-1.27 \mathrm{~V}\right.$ vs $\mathrm{SCE}$ (calibrated using $\mathrm{Fc} / \mathrm{Fc}^{+}$)] shows little difference from that of $\mathbf{1 7}^{\prime}$. [ $E_{1 / 2}(\mathrm{DMF})=-1.24 \mathrm{~V}$ vs SCE (calibrated using $\mathrm{Fc} /$ $\left.\mathrm{Fc}^{+}\right)$]. Accordingly, permitting a freer rotation than seen in $\mathbf{1 7}^{\prime}$ by extending the tether between the two pyridine-derived rings does not lead to enhanced donor properties.

The other site of relatively easy variation in $\mathbf{8}$ was the dialkylamino group. 4-Pyrrolidinopyridine and 4-guanidinopyridine are significantly better catalysts $[42,43]$ in acylation reactions than 4-DMAP. Their effectiveness depends on the delocalization of the electron pair on the 4-substituent into the pyridine ring. Accordingly, the disalts $\mathbf{2 1}$ and $\mathbf{2 2}$ were prepared from these 4-substituted pyridines $[43,45]$ and converted into their hexafluorophosphates 21' and 22', and then examined by cyclic voltammetry. Each showed a reversible two-electron redox wave (Figure 6). Redox equilibria related to 21 showed that the corresponding donor $\mathbf{2 3}$ was a stronger donor than donor $\mathbf{8}$ by about $90 \mathrm{mV}$ for the transfer of its first electron, while the second electron occurs at the same potential as seen for donor $\mathbf{8}$, while $\mathbf{2 4}$ transferred both of its electrons at the same potential and was within $10 \mathrm{mV}$ of $\mathbf{1 7}^{\prime}$.

The reactivity of these two donors was also investigated with substrate $\mathbf{2 7}$. Here, $\mathbf{2 3}$ and $\mathbf{2 4}$ were prepared in situ from $\mathbf{2 5}^{\prime}$ and 26. This afforded the reductive de-iodination product $\mathbf{2 8}$ in good yield ( $84 \%$ when using $\mathbf{2 5}^{\prime}$, and $68 \%$ when using $\mathbf{2 6}$ ).

These results are in accord with the previous reactions of donor $\mathbf{8}$, and show that significantly more powerful donors than $\mathbf{8}$ cannot be attained simply by altering the tether length between the two pyridine units. Similarly, simple modifications to the

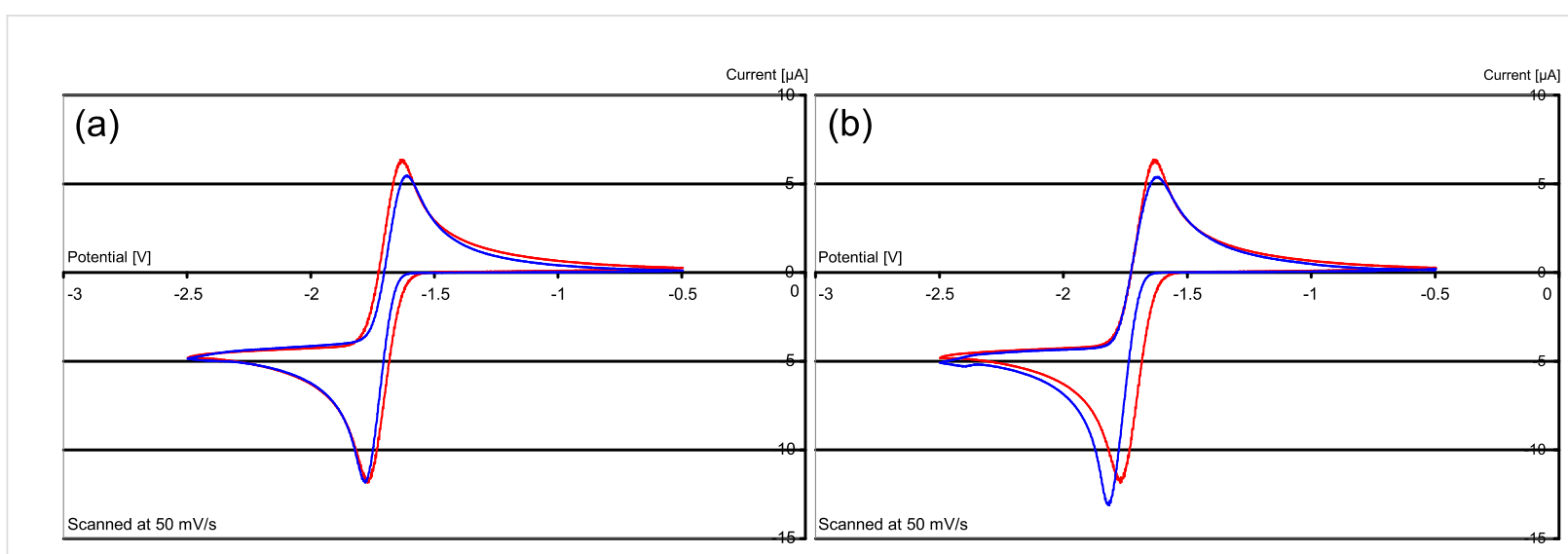

Figure 4: (a) Cyclic voltammograms vs. Fc/Fc' of $17^{\prime} \leftrightarrow 8$ (red) and $18^{\prime} \leftrightarrow 15$ (blue) and (b) of $17^{\prime} \leftrightarrow 8$ (red) and $20^{\prime} \leftrightarrow 19$ (blue) 
<smiles>[R]C1=CC(=C2C=C([R])C=CN2C)N(C)C=C1</smiles>

19, $\mathrm{R}=\mathrm{NMe}_{2}$

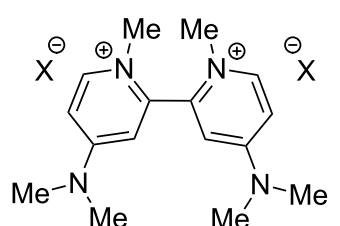

20, $X=1$ 20', $X=\mathrm{PF}_{6}$

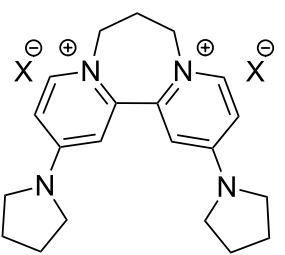

21, $X=1$

21', $X=P F_{6}$

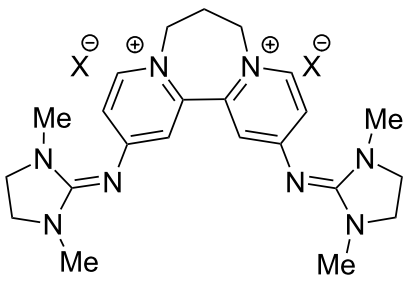

22, $X=1$

22', $X=\mathrm{PF}_{6}$<smiles>[R]C1=CC2=C3C=C([R])C=CN3CCCN2C=C1</smiles>

23, $\mathrm{R}=\mathrm{N}\left(\mathrm{CH}_{2}\right)_{4}$

24, $\mathrm{R}=\mathrm{N}\left[\mathrm{C}(\mathrm{N}-\mathrm{Me}) \mathrm{CH}_{2}\right]_{2}$<smiles>Ic1ccc(OCCCc2ccccc2)cc1</smiles>

27

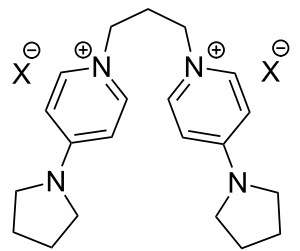

25, $X=1$

25', $X=\mathrm{PF}_{6}$

$\mathbf{2 5}$ or 26 (1.5 equiv), $\mathrm{NaH}, \mathrm{DMF}, 16$ h, r.t.

Figure 5: Electron donors, their oxidized dications and their reactions with 27.
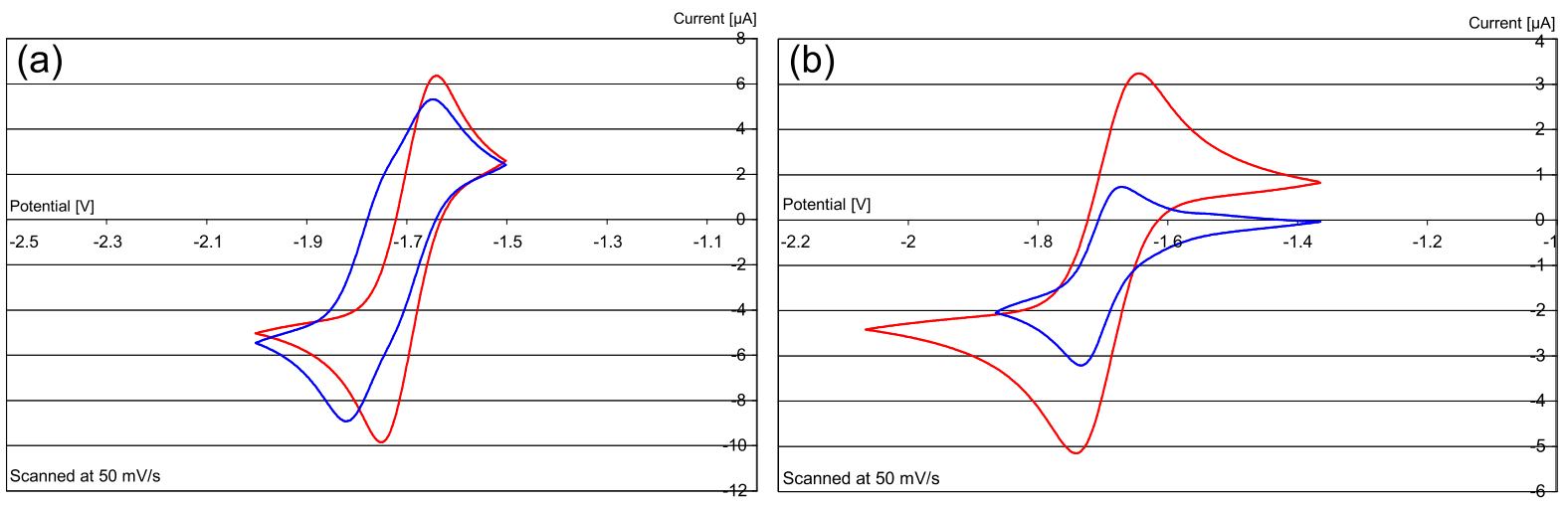

Figure 6: Cyclic voltammograms vs Fc/Fc ${ }^{+}$(a) of $17^{\prime} \leftrightarrow \mathbf{8}$ (red) and $\mathbf{2 1} 1^{\prime} \leftrightarrow \mathbf{2 3}$ (blue) and (b) of $\mathbf{1 7} 7^{\prime} \leftrightarrow \mathbf{8}$ (red) and $\mathbf{2 2} 2^{\prime} \leftrightarrow \mathbf{2 4}$ (blue) (at half the concn used for 17')

4'-substituent do not lead to very large changes in the redox properties of $\mathbf{8}$. [The oxidation potentials of these new donors and the preceding examples mentioned in this paper are tabu- lated below in Table 1.] These outcomes are already helping our design of new, versatile and more powerful organic electron donors. 
Table 1: Oxidation potentials of organic electron donors ${ }^{a}$

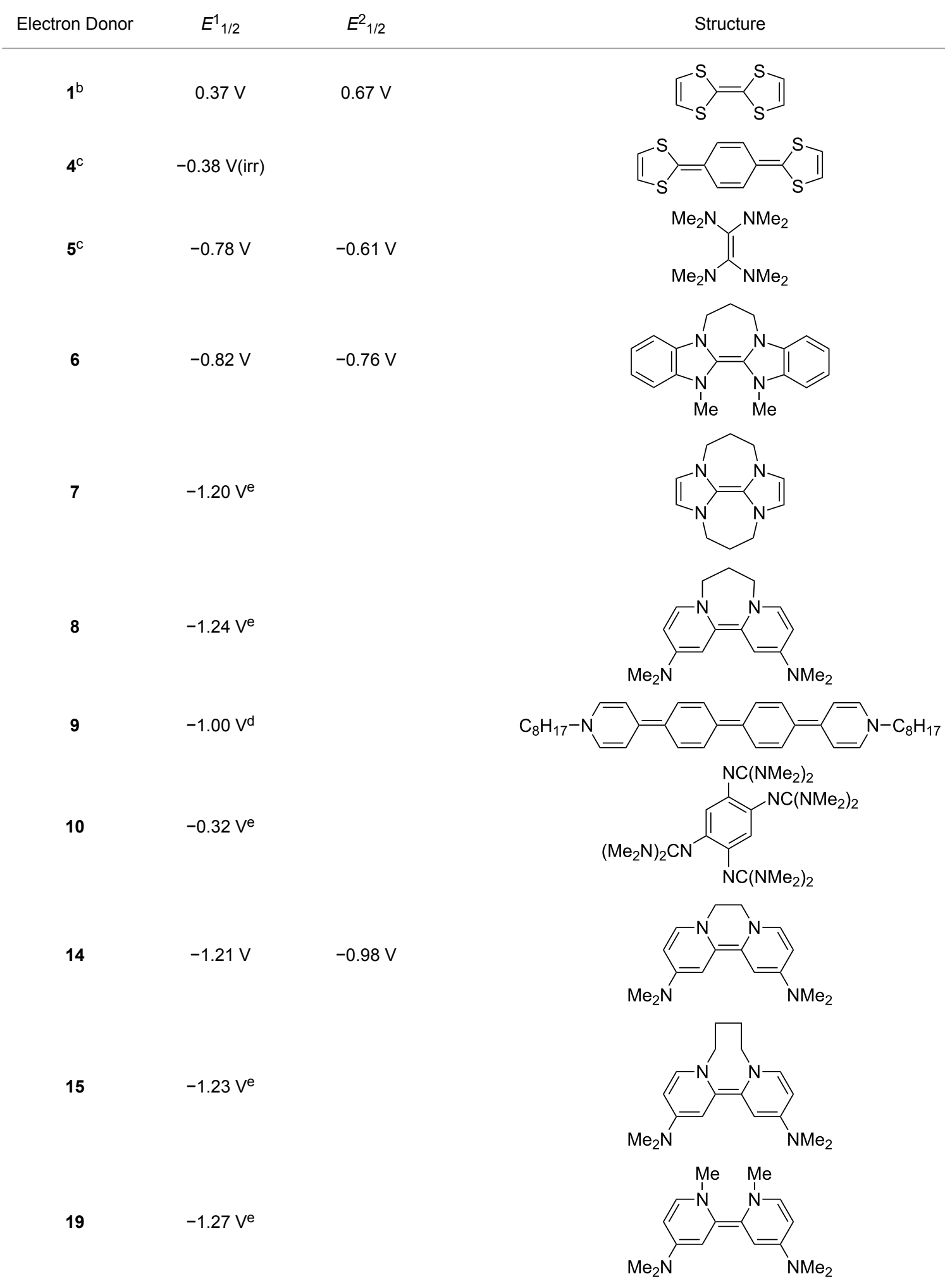


Table 1: Oxidation potentials of organic electron donors ${ }^{a}$ (continued)

23

$-1.33 \mathrm{~V}$

$-1.24 \mathrm{~V}$

24

$-1.24 V^{e}$<smiles>C1=CN2CCCN3C=CC(N4CCCC4)=CC3=C2C=C1N1CCCC1</smiles><smiles>CN1CCN(C)C1=Nc1ccn2c3cn(ccc(N=C4N(C)CCN4C)c-3c1)CCC2</smiles>

${ }^{a}$ All numbers have been converted for comparison with SCE; all experiments recorded in DMF, except where otherwise stated.

${ }^{\mathrm{b}}$ Recorded in DCM.

'Recorded in MeCN.

decorded in THF.

eTwo-electron wave.

\section{Supporting Information}

Supporting Information features detailed information on experimental procedures and compound characterisation.

\section{Supporting Information File 1}

Experimental Part

[http://www.beilstein-journals.org/bjoc/content/

supplementary/1860-5397-6-73-S1.pdf]

\section{Acknowledgements}

We thank EPSRC, University of Strathclyde and AstraZeneca for funding and EPSRC Mass Spectrometry Centre, Swansea for mass spectra. We also thank the National Crystallography Service at Southampton for data collection.

\section{References}

1. Segura, J. L.; Martin, N. Angew. Chem., Int. Ed. 2001, 40, 1372. doi:10.1002/1521-3773(20010417)40:8<1372::AID-ANIE1372>3.0.CO; 2-I

2. Murphy, J. A.; Lampard, C.; Lewis, N. J. Chem. Soc., Chem. Commun. 1993, 295. doi:10.1039/C39930000295

3. Begley, M. J.; Murphy, J. A.; Roome, S. J. Tetrahedron Lett. 1994, 35, 8679. doi:10.1016/S0040-4039(00)78470-X

4. Murphy, J. A.; Fletcher, R. J.; Lampard, C.; Lewis, N. J. Chem. Soc., Perkin Trans. 1 1995, 623. doi:10.1039/P19950000623

5. Murphy, J. A.; Rasheed, F.; Roome, S. J.; Lewis, N. Chem. Commun. 1996, 737. doi:10.1039/CC9960000737

6. Fletcher, R. J.; Hibbs, D. E.; Hursthouse, M.; Lampard, C.; Murphy, J. A.; Roome, S. J. Chem. Commun. 1996, 739. doi:10.1039/CC9960000739
7. Kizil, M.; Lampard, C.; Murphy, J. A. Tetrahedron Lett. 1996, 37, 2511. doi:10.1016/0040-4039(96)00306-1

8. Murphy, J. A.; Rasheed, F.; Roome, S. J.; Scott, K. A.; Lewis, N. J. Chem. Soc., Perkin Trans. 1 1998, 2331. doi:10.1039/a802971g

9. Fletcher, R.; Kizil, M.; Lampard, C.; Murphy, J. A.; Roome, S. J. J. Chem. Soc., Perkin Trans. 1 1998, 2341. doi:10.1039/a802974a

10. Callaghan, O.; Lampard, C.; Kennedy, A. R.; Murphy, J. A. Tetrahedron Lett. 1999, 40, 161. doi:10.1016/S0040-4039(98)80047-6

11. Callaghan, O.; Lampard, C.; Kennedy, A. R.; Murphy, J. A. J. Chem. Soc., Perkin Trans. 1 1999, 995. doi:10.1039/a900335e

12. Murphy, J. A. The Radical-Polar Crossover Reaction. In Radicals in Organic Synthesis, Volume 1: Basic Principles; Renaud, P.; Sibi, M. P., Eds.; Wiley-VCH: Germany, 2001; pp 298-315.

13. Sato, M.; Lakshmikantham, M. V.; Cava, M. P.; Garito, A. F. J. Org. Chem. 1978, 43, 2084. doi:10.1021/jo00404a064

14. Burkholder, C.; Dolbier, W. R.; Medebielle, M. J. Org. Chem. 1998, 63, 5385. doi:10.1021/jo980201+

15. Takechi, N.; Ait-Mohand, S.; Medebielle, M.; Dolbier, W. R., Jr.. Tetrahedron Lett. 2002, 43, 4317. doi:10.1016/S0040-4039(02)00800-6

16. Since, M.; Terme, T.; Vanelle, P. Tetrahedron 2009, 65, 6128. doi:10.1016/j.tet.2009.05.036

17. Juspin, J.; Giuglio-Tonolo, G.; Terme, T.; Vanelle, P. Synthesis 2010, 844. doi:10.1055/s-0029-1218590

18. Ames, J. R.; Houghtaling, M. A.; Terrian, D. L.; Mitchell, T. P. Can. J. Chem. 1997, 75, 28. doi:10.1139/v97-004

19. Shi, Z.; Thummel, R. P. J. Org. Chem. 1995, 60, 5935. doi:10.1021/jo00123a034

20. Thummel, R. P.; Goulle, V.; Chen, B. J. Org. Chem. 1989, 54, 3057. doi:10.1021/jo00274a019

21. Murphy, J. A.; Khan, T. A.; Zhou, S. Z.; Thomson, D. W.; Mahesh, M. Angew. Chem., Int. Ed. 2005, 44, 1356. doi:10.1002/anie.200462038

22. Taton, T. A.; Chen, P. Angew. Chem. 1996, 108, 1098. doi:10.1002/ange.19961080926

Angew. Chem., Int. Ed. Engl. 1996, 35, 1011.

doi:10.1002/anie.199610111 
23. Hunig, S.; Sheutzov, D.; Schlaf, H. Justus Liebigs Ann. Chem. 1973, 765,126

24. Murphy, J. A.; Zhou, S.-Z.; Thomson, D. W.; Schoenebeck, F.; Mahesh, M.; Park, S. R.; Tuttle, T.; Berlouis, L. E. A. Angew. Chem., Int. Ed. 2007, 46, 5178. doi:10.1002/anie.200700554

25. Murphy, J. A.; Schoenebeck, F.; Zhou, S.-Z.; Uenoyama, Y.; Miclo, Y.; Tuttle, T. J. Am. Chem. Soc. 2007, 129, 13368. doi:10.1021/ja074417h

26. Murphy, J. A.; Garnier, J.; Park, S. R.; Schoenebeck, F.; Zhou, S. Z.; Turner, A. T. Org. Lett. 2008, 10, 1227. doi:10.1021/ol800134g

27. Garnier, J.; Murphy, J.; Zhou, S.-Z.; Turner, A. Synlett 2008, 2127. doi:10.1055/s-2008-1078242

28. Cutulic, S. P. Y.; Murphy, J. A.; Farwaha, H.; Zhou, S.-Z.; Chrystal, E. Synlett 2008, 2132. doi:10.1055/s-2008-1078240

29. Cutulic, S. P. Y.; Findlay, N. J.; Zhou, S.-Z.; Chrystal, E. J. T.; Murphy, J. A. J. Org. Chem. 2009, 74, 8713. doi:10.1021/jo901815t

30. Porter, W. W.; Vaid, T. P.; Rheingold, A. L. J. Am. Chem. Soc. 2005, 127, 16559. doi:10.1021/ja053084q

31. Porter, W. W.; Vaid, T. P. J. Org. Chem. 2005, 70, 5028. doi:10.1021/jo050328g

32. Vaid, T. P.; Lytton-Jean, A. K.; Barnes, B. C. Chem. Mater. 2003, 15, 4292. doi:10.1021/cm034646c

33. Peters, A.; Kaifer, E.; Himmel, H.-J. Eur. J. Org. Chem. 2008, 5907. doi:10.1002/ejoc.200800900

34. Wang, H. J.; Shi, J.; Fang, M.; Li, Z.; Guo, Q. X. J. Phys. Org. Chem. 2010, 23, 75. doi:10.1002/poc. 1590

35. Peters, A.; Trumm, C.; Reinmuth, M.; Emeljanenko, D.; Kaifer, E.; Himmel, H.-J. Eur. J. Inorg. Chem. 2009, 3791. doi:10.1002/ejic.200900399

36. Lappert, M. F.; Alvarez, S.; Aullon, G.; Fandos, R.; Otero, A.; Rodriguez, A.; Rojas, S.; Terreros, P. Eur. J. Inorg. Chem. 2009, 1851. doi:10.1002/ejic.200801113

37. Vitske, V.; König, C.; Hübner, O.; Kaifer, E.; Himmel, H.-J. Eur. J. Inorg. Chem. 2010, 115. doi:10.1002/ejic.200900724

38. Elbl-Weiser, K.; Krieger, C.; Staab, H. A. Angew. Chem., Int. Ed. Engl. 1990, 29, 211. doi:10.1002/anie.199002111

39. Andrieux, C. P.; Pinson, J. J. Am. Chem. Soc. 2003, 125, 14801. doi:10.1021/ja0374574

40. Otero, M. D.; Batanero, B.; Barba, F. Tetrahedron Lett. 2006, 47, 8215. doi:10.1016/j.tetlet.2006.09.132

41. Connelly, N. G.; Geiger, W. E. Chem. Rev. 1996, 96, 877. doi:10.1021/cr940053x

42. Spivey, A. C.; Arseniyadis, S. Angew. Chem., Int. Ed. 2004, 43, 5436. doi:10.1002/anie.200460373

43. Hassner, A.; Krepski, L. R.; Alexanian, V. Tetrahedron 1978, 34, 2069. doi:10.1016/0040-4020(78)89005-X

44. Bock, H.; Ruppert, K.; Merzweiler, K.; Fenske, D.; Goesmann, H. Angew. Chem., Int. Ed. Engl. 1989, 28, 1684. doi:10.1002/anie.198916841

45. Narayan, S.; Seelhammer, T.; Gawley, R. E. Tetrahedron Lett. 2004, 45, 757. doi:10.1016/j.tetlet.2003.11.030

\section{License and Terms}

This is an Open Access article under the terms of the Creative Commons Attribution License

(http://creativecommons.org/licenses/by/2.0), which permits unrestricted use, distribution, and reproduction in any medium, provided the original work is properly cited.

The license is subject to the Beilstein Journal of Organic Chemistry terms and conditions:

(http://www.beilstein-journals.org/bjoc)

The definitive version of this article is the electronic one which can be found at:

doi:10.3762/bjoc. 6.73 